\title{
GÉNERO E PERDA EMOCIONAL PROFUNDA NA VELHICE ${ }^{1}$
}

\author{
Jenny Sousa \& Maria Manuel Baptista
}

\begin{abstract}
ReSUMO
A perda do cônjuge na velhice tem um profundo impacto na vida e no bem-estar da pessoa idosa, uma vez que cria uma série de discrepâncias entre o mundo que se conhecia e aquele que passa a existir. Este aspeto é ainda mais marcante se, a par da viuvez, o/a enlutado/a se vê também desapossado do seu lar, numa institucionalização que acentua a sua desestruturação identitária. Neste contexto de viuvez e de institucionalização permanente, a significação que a pessoa idosa atribui à perda, e a sua capacidade de (re)construção da práxis quotidiana, encontra-se intimamente relacionada com condições críticas que favorecem um perfil de maior ou menor capacidade de superar o luto. De entre as várias condições críticas destaca-se o género, enquanto principal elemento diferenciador de comportamentos nos processos de adaptação às perdas. A partir destes pressupostos, este artigo apresenta-se estruturado em duas partes fundamentais: num primeiro momento faremos um enquadramento teórico, focando os aspetos mais marcantes do luto na velhice e do papel da institucionalização neste contexto de perda emocional profunda; num segundo momento, apresentaremos, analisaremos e discutiremos os resultados obtidos numa investigação qualitativa produzida no âmbito do Programa Doutoral em Estudos Culturais.
\end{abstract}

\section{Palavras-chave}

Velhice; luto; género; Estudos Culturais

\section{INTRODUÇÃO}

A velhice é uma etapa vital peculiar. Embora já se tenha ultrapassado a ideia tradicional de crescimento, maturidade e decadência (Gomes, 2010), a verdade é que o processo de envelhecimento acarreta um conjunto de perdas que podem influenciar a qualidade de vida da pessoa idosa e o seu grau de satisfação subjetiva (Afonso, 2012; Paúl, 2006; Santos \& Encarnação, 1998).

De entre os vários tipos de perdas podem-se destacar as que ocorrem nos domínios corporal, cognitivo e psicológico e as que se devem ao envelhecimento social e à consequente perda de papéis sociais (Barreto, 2006). Amplamente associado a este último está a perda das pessoas que são mais próximas e que detêm influência no próprio sentido de identidade. A perda dos amigos, dos familiares, mas, sobretudo, do cônjuge, constitui-se como um dos grandes fatores de stress na vida das pessoas idosas uma vez que obriga a uma reconstrução do mundo e da vida que passa a ter contornos

\footnotetext{
' Os dados aqui apresentados integram-se numa investigação mais ampla, conduzida no âmbito de um projeto de Doutoramento em Estudos Culturais, da responsabilidade conjunta das Universidades do Minho e de Aveiro, cujo tema se centra no estudo da forma como as pessoas idosas e as estruturas residenciais se articulam na superação da perda emocional profunda, especificamente por perda de cônjuge, e no modo como as atividades socioculturais podem constituir-se como estratégias facilitadoras de adaptação à perda.
} 
indiscutivelmente diferentes (Bennet, 1997; Carr, 2004; Carr, Housa, Kessler, Nesse, Sonnega \& Wortman, 2000; Rebelo, 2009). Tal como explica Colin Parkes (1998), em qualquer luto muito raramente se percebe com exatidão o que foi perdido. A perda do cônjuge pode significar, ou não, a perda do/a parceiro/a sexual, do/a companheiro/a, do apoio financeiro, do apoio em tarefas específicas, entre outros. Por isso, uma perda traz consigo outras perdas, obrigando a uma (re)construção identitária e à aprendizagem de novos papéis sociais.

Este processo de reconstrução é denominado de luto. Segundo John Bowlby (1984), o luto é um processo de transição que engloba uma variedade de procedimentos de adaptação à perda. Este processo, apesar de ser altamente individual, é influenciado por um conjunto de fatores, os chamados determinantes do luto. Segundo a literatura da especialidade (Bowlby, 1984; Parkes, 1998; Rebelo, 2007; Twycross, 2003; Worden, 2002) dois dos mais importantes determinantes são a idade e o sexo da pessoa enlutada assim como, os acontecimentos de vida stressantes concorrentes, ou seja, as mudanças e as crises que podem ocorrer após a morte. Temos consciência que todos estes determinantes são importantes quando queremos compreender os diferenciados processos de enfrentamento e de elaboração do luto. Contudo, neste momento, iremos analisar com maior pormenor apenas os determinantes que dizem respeito à idade e ao sexo.

Para Barros de Oliveira (2010), é preciso ter em conta que o processo de luto na velhice é complexo, ambíguo e muitas vezes penoso e inultrapassável, dependendo da idiossincrasia da pessoa e do apoio do contexto social envolvente. Embora a experiência deste tipo de perdas seja influenciada por inúmeros aspetos, existem, contudo, alguns padrões de luto na idade adulta avançada que merecem ser observados mais de perto. A dissolução do casal longevo, por morte de um dos cônjuges, empurra o sobrevivente para uma realidade complexa, onde o sentido do self se vê inevitavelmente alterado. Particularmente difícil no primeiro ano a seguir ao falecimento, este período é especialmente marcado pelo alto nível de mortalidade e suicídio (Erlangsen, Jeune, Bille-Brahe \& Vaupel, 2004; Fry, 1998), devido precisamente à sensação de perda, desorientação e solidão, mas sobretudo à desagregação dos papéis que eram o pilar estruturador da identidade (McGoldrick \& Walsh, 1998). Na verdade, e tal como explica Parkes (1998), a perda do cônjuge é um acontecimento traumático pelas mudanças de atitudes que ocorrem no/a enlutado/a, mas também pela forma como a própria sociedade passa a encarar o/a viúvo/a. Esta mudança de atitudes, que ocorre na sociedade em relação à pessoa que perde o cônjuge, é intitulada pelo autor de "estigma". Sendo o casamento, culturalmente, uma parte integrante da organização social, providenciando identidade pessoal e social, quando ocorre a viuvez ocorre, também, um esvaziamento do papel social.

Temos consciência da relação complexa entre luto e características do casamento, contudo, também temos conhecimento que, independentemente da satisfação conjugal, a perda do cônjuge na adultez tardia obriga sempre a uma reconstrução da identidade pessoal e social (Carr et al., 2000). Nesta linha de argumentação, e ainda na ótica de Colin Parkes (1998), as mulheres saem sempre da experiência de luto com mais problemas psicológicos que os homens, trazendo à liça a importância do género na adaptação 
à perda e na reconstrução identitária na velhice. Contudo, no que respeita a este determinante em concreto - o género - nem todos os estudos chegam aos mesmos resultados.

De facto, e tal como explica Deborah Carr (2004), as diferenças de género na adaptação à viuvez na adultez tardia têm sido estudadas extensivamente, mas com resultados ainda bastante inconclusivos. Existem estudos que apontam que as mulheres sofrem de uma maior angústia que os homens na adaptação à perda (Carr et al., 2000; $\mathrm{Ha}, \mathrm{Carr}$, Utz \& Nesse, 2006; Parkes, 1998); outros estudos indicam que os homens idosos têm maiores dificuldades em elaborar a perda da companheira e que precisam de mais tempo para superar o luto do que as mulheres (Erlangsen et al., 2004; Stroebe, 1998). Segundo Neto (2004, 2000), independentemente das diferenças entre sexos serem biológicas, psicológicas ou sociais, diversos estudos deixaram claro que existem, de facto, diferenças. Neste sentido, os estudos têm apontado para o facto de os sujeitos do género feminino serem muitas vezes superiores na capacidade verbal e na linguagem, na descodificação de pistas não-verbais, em particular as expressões faciais, uma vez que parecem possuir maior sensibilidade emocional; também por este motivo, parecem apresentar uma maior tendência para a depressão. No que toca aos sujeitos do género masculino, os estudos tendem a indicar que eles possuem maiores aptidões em tarefas quantitativas e espaciais e são mais agressivos. Ainda segundo o mesmo autor,

as mulheres em média mostram mais comportamentos sócio-emocionais positivos, tais como agir de modo amigável, concordar com outras pessoas, oferecer apoio emocional. Os homens mostram mais comportamentos orientados para a tarefa, tais como dar e pedir opiniões, tentar resolver a tarefa do grupo. [...] Em suma, estas diferenças no comportamento em grupo sugerem que os homens estão mais focalizados na concretização de tarefas e de recompensas e as mulheres são mais focadas pelos aspetos sociais da interação e em manter sentimentos positivos entre os membros do grupo. (Neto, 2000, p. 87)

Assim, a explicação para o facto de as mulheres terem vidas emocionais mais extremas que os homens

pode encontrar-se sobretudo ao nível dos papéis de género que são prescritos pela sociedade. Os papéis de género tradicionais das mulheres têm em conta maiores responsabilidades em cuidar dos outros que podem encorajar mais respostas emocionais nas mulheres que nos homens. Tal pode ter como resultado que as mulheres podem ter mais vontade de experienciar $\mathrm{e}$ de exprimir emoções. (Neto, 2004, p. 369)

Também as fontes de felicidade são dissemelhantes para os indivíduos do sexo masculino e para os indivíduos do sexo feminino: os homens são mais afetados pelo trabalho e pela satisfação económica; as mulheres são mais afetadas pelos seus filhos, pela saúde da sua família, sendo também muito mais autocríticas (Neto, 2004). 
Apesar de, tal como o autor sublinha, as diferenças de género serem mais pequenas do que dentro de cada um dos grupos de homens e mulheres, não podemos deixar de ter presente que as influências socioculturais relacionadas com as questões de género são marcantes e influenciam o comportamento, o autoconceito, as escolhas e as perceções dos indivíduos e, como tal, devem ser tomadas em consideração quando se estuda a (re)construção identitária de pessoas idosas que viveram toda a vida condicionadas pelo "o que é ser homem, o que é ser mulher" (Ribeiro, 2002, p. 124). Tal como explica Carr (2004), na realidade, as diferenças de género na superação da perda estão intimamente relacionadas com as diferenças de género que marcaram a socialização do casal e com os papéis familiares que ao longo de toda a vida foram definidos pelo sexo. Assim sendo, explica ainda a autora, quanto mais a vivência do casal for influenciada pelos papéis de género, maiores serão as dificuldades em superar o luto e adaptar-se à perda do cônjuge. Nesta linha, diversos estudos (Carr, 2004; Guinther, Segal \& Bogaards, 2003; Ha et al., 2006) revelam que a divisão tradicional das tarefas e dos papéis coloca diferentes desafios às viúvas e aos viúvos e que estes são influenciados na adaptação à perda conjugal pelos papéis de género com os quais foram socializados. Assim, enquanto as mulheres tendem a fazer mais o trabalho doméstico do que os seus maridos são, também, muito mais propensas a gerir as tarefas relacionadas com o bem-estar da família. Normalmente, possuem uma rede de fortes ligações afetivas com familiares e vizinhos. Contudo, são mais dependentes a nível económico, financeiro e legal. Ainda segundo os mesmos estudos, os homens habitualmente dirigem as suas energias no cumprimento da função do sustento da família, nas tarefas da manutenção financeira e possuem redes mais largas de contactos e de ligações com a comunidade.

Assim sendo, superar o luto implica organizar os múltiplos fatores interindividuais com os aspetos intraindividuais. Percebemos como a cultura fornece auxílio no processo de integração da morte e de transformação dos sobreviventes, determinando o significado que o indivíduo dá à morte, à vida e aos modos de adaptação à perda (Papalia et al., 2006). Nesta adaptação à perda, as estratégias utilizadas pelos/as enlutados/as são condicionadas pela perceção da comunidade, e do/a próprio/a, sobre o comportamento ajustado à viúva e ao viúvo (Parkes, 1998; Rebelo, 2009; Twycross, 2003). Neste sentido, as estratégias de suporte emocional de superação do luto estão arreigadas nos referenciais culturais e são influenciadas por quadros simbólicos específicos que determinam a ressignificação que o/a enlutado/a faz da vida e da forma de a viver. Por isso, as estratégias utilizadas para a elaboração do luto são sempre formas de eficácia simbólica de relação com o mundo e implicam, da parte da pessoa idosa, um sentimento de autonomia e controlo para encontrar os recursos necessários para recomeçar (Parkes, 1998; Rebelo, 2009; Twycross, 2003).

Conforme pode ler-se na literatura da especialidade (Parkes, 1998; Rebelo, 2007; Twycross, 2003), se o meio cultural e social oferecer as condições para que a pessoa idosa enlutada se possa desenvolver, consoante as suas capacidades, interesses e necessidades próprias e específicas, apesar de todos os problemas, a perda do cônjuge pode ter um efeito de crescimento e maturidade. Descobrindo e realizando as suas próprias 
possibilidades, a superação do luto é possível, independentemente da idade e do sexo. Neste processo não há receitas, mas um conjunto de respostas adaptativas que podem estar encerradas numa eventual continuação da antiga atividade profissional, na adesão a uma nova atividade, na realização de atividades culturais e artísticas, em viagens, no reforço das relações familiares e no aumento da vida relacional e associativa (Fonseca, 2005). Contudo, a capacidade do sujeito para lidar com a perda é significativamente afetada se esta tiver um carácter cumulativo e implicar mudanças estruturais (Carr, 2004; Parkes, 1998). Assim, no âmbito deste trabalho interrogámo-nos relativamente ao que acontece quando, após o falecimento do cônjuge, os/as viúvos/as são obrigados a abandonar o espaço que partilharam com o companheiro de vida, quer dizer, quando a morte do cônjuge traz consigo a institucionalização.

\section{A VIUVEZ E A INSTITUCIONALIZAÇÃo: OS DOIS FATORES DE STRESS}

A viuvez e a institucionalização constituem dois dos grandes fatores de stress da vida adulta idosa pela exigência do esforço adaptativo e pelo impacto emocional que causam (Moragas, 1998; Paúl, 1997). Deixar o lar, espaço de recordações e de recortes de significados, de conforto emocional e de identidade, é mais um duro golpe, uma perda com amplas repercussões (McGoldrick \& Walsh, 1998). Ao serem forçadas a sair dos seus lares — devido a motivos que vão desde a inabilidade de morar sozinho, à falta de condições monetárias para manter a casa ou até à falta de condições da própria habitação -, as pessoas idosas abandonam o ambiente que era do casal, a última ligação ao ente querido falecido e ao próprio sentido do self. As perdas acumulam-se e a solidão intensifica-se.

Neste quadro, como podem as estruturas residenciais contribuir para a superação das perdas emocionais profundas da pessoa idosa enlutada? Tal como as pessoas idosas não institucionalizadas, também as pessoas residentes em estruturas residenciais continuam viradas para o futuro e possuem mecanismos de superação e de coping (Afonso, 2012; Barreto, 2006). Todavia, para que as pessoas idosas institucionalizadas acionem estes mecanismos é preciso que lhes seja dada a autonomia e a liberdade necessárias, e que a atmosfera residencial seja o mais humanizada e personalizada possível (Born, 2002). Assim, um aspeto crucial é favorecer a preservação da identidade e do autoconceito da pessoa idosa, bem como, a perceção de controlo acerca da sua própria vida e em relação ao meio institucional. Na realidade, o controlo percebido é extremamente importante como estratégia de coping - estratégias utilizadas pelos sujeitos para responder a situações stressantes (Afonso, 2012) — na superação das perdas, nomeadamente na viuvez. Se este aspeto é importante para as pessoas idosas não institucionalizadas, ele assume uma relevância vital para os indivíduos que residem permanentemente em estruturas residenciais.

Intimamente relacionado com o controlo estão as trocas sociais (Fonseca, 2005). As alianças de confiança, quer com familiares, quer com companheiros da instituição e até da equipa de profissionais, são também importantes estratégias de combate à solidão, de adaptação à perda e de (re)construção da identidade, última etapa do processo de luto. 
Neste sentido, na superação do processo de luto confluem fatores individuais, sociais e culturais, destacando-se o género enquanto elemento crucial. Com efeito, sobretudo nas pessoas idosas que mais facilmente se reconhecem em papéis tendencialmente estereotipados de género, este indicador deve ser tido em conta enquanto elemento estruturador das práticas sociais sendo, até, uma dimensão-chave na diferenciação simbólica, social e pessoal dos padrões de vida das pessoas idosas institucionalizadas. Com a entrada definitiva numa estrutura residencial, as pessoas idosas perdem a sua individualidade bem como, o acesso aos recursos que eventualmente poderiam utilizar na adaptação à perda do cônjuge (as atividades de rotina diária, as lides domésticas, a rede de vizinhança e amigos, entre outros). Assim sendo, como elaboram os seus lutos as pessoas que são categorizadas numa orientação uniformizadora? Qual a importância do género nestes contextos de institucionalização da anomia (Bourdieu, 1989), onde o controle rígido da vida de cada pessoa idosa parece ser o fundamento essencial do todo organizacional?

Precisamente no sentido de compreendermos de que forma o sexo influencia na significação da perda e na capacidade de adaptação e de (re)construção da práxis quotidiana num contexto de viuvez e de institucionalização permanente, desenvolvemos o estudo que a seguir apresentamos.

\section{O ESTUDO}

Os resultados discutidos ao longo deste artigo resultam de uma investigação, elaborada a partir do quadro teórico dos Estudos Culturais, onde tentamos compreender de que modo o género influencia a reconstrução identitária da pessoa idosa institucionalizada na adaptação às perdas emocionais profundas.

Por pretendermos um estudo empírico dos significados dos comportamentos que se constroem nas interações entre os indivíduos, conduzimos uma pesquisa que se insere no paradigma geral de investigação qualitativa, com fortes contornos etnográficos, enriquecido pelas perspetivas humanístico-interpretativa, fenomenológica e simbólica.

O método principal de recolha de dados e de produção do acervo fundamental da informação foram as "mini-histórias” de vida (O’Neill, 2009), realizadas a quinze pessoas idosas residentes em quatro estruturas residenciais da região de Leiria. Uma vez que pretendíamos perceber como é que o género das pessoas idosas institucionalizadas influencia a sua adaptação à perda emocional profunda, "perda do cônjuge na velhice" foi o critério de escolha dos nossos sujeitos, tendo sido convidadas a participar todas as pessoas idosas que perderam o cônjuge após os 65 anos e que, por causa dessa perda, entraram a título permanente para um estrutura residencial de apoio a idosos. Um aspeto fundamental para poderem ser participantes do estudo prendia-se com a capacidade de entendimento e comunicação verbal. Atendendo a estes critérios, dos 209 sujeitos residentes nas quatro instituições, foram selecionados 15 indivíduos que passaram a constituir o grupo de sujeitos da nossa investigação. 


\subsection{OS SUJEITOS}

Os sujeitos foram agrupados segundo as suas caraterísticas e de acordo com os fatores individuais e contextuais que nos interessava, prioritariamente, estudar: idade, sexo, lugar de proveniência, habilitações académicas, rendimento económico e participação em atividades culturais e de animação.

Assim, numa descrição geral dos sujeitos participantes do estudo podemos dizer que os entrevistados tinham, na sua esmagadora maioria, idades compreendidas entre os 80 e os 90 anos; no que se refere ao sexo, 10 sujeitos eram do sexo feminino e 5 do sexo masculino; no que respeita às habilitações académicas, 5 sujeitos não possuíam qualquer nível de escolaridade, 6 sujeitos possuíam escolaridade até à $4^{\text {a }}$ classe e 4 sujeitos tinham escolaridade até ao ensino secundário. Relativamente ao rendimento económico, 4 sujeitos possuíam um nível baixo de rendimento, 5 sujeitos um nível médio e 6 sujeitos um nível elevado de rendimento económico. Por fim, e no que concerne à participação em atividades culturais e de animação, 9 sujeitos participavam regularmente, enquanto 6 sujeitos não participavam em qualquer atividade desta natureza. No contexto deste estudo não serão exploradas todas as variáveis enunciadas, mas apenas nos teremos à variável género².

\subsection{A Recolha e a ANÁlise dos dados}

Tendo como pano de fundo os critérios explicados no ponto anterior, o primeiro contacto com os sujeitos foi feito através das direções das estruturas residenciais onde viviam. Em todos os casos foram as direções das instituições que levaram a cabo a tarefa de apresentar a investigadora a cada um dos indivíduos. Este primeiro contacto era, essencialmente, um momento de conhecimento mútuo, onde começava a desenhar-se uma relação significativa e de proximidade.

Neste primeiro encontro era agendado, ainda, o encontro seguinte. Quanto ao local de realização da entrevista, tentou-se, em todos os casos, que estas fossem feitas em espaços privados, preservados da entrada de alguém estranho à investigação.

Porque se remexe em baús trancados, tínhamos a consciência de que este manancial de recordações e emoções poderia provocar um "re-experimentar dos sentimentos e das emoções que lhes estão associados" (Brandão, 2007, p. 2); por isso, foi nossa preocupação realizar a entrevista da forma mais respeitadora possível da personalidade do sujeito, deixando a narrativa fluir ao ritmo de cada indivíduo (Bertaux, 1999; Ferrarotti, 2007). Assim, as entrevistas que aplicámos seguiram a estrutura aconselhada por Medrano e Cortés (2007). Neste sentido, e tal como já referimos, havia uma fase prévia à entrevista que consistia na apresentação, da investigadora e do estudo, mas também dos próprios entrevistados. Neste primeiro contacto, ficava feito, desde logo, um contrato implícito (Bertaux, 1999). A fase seguinte centrava-se mais em perguntas abertas

\footnotetext{
${ }^{2}$ No caso de o leitor estar interessado em conhecer toda a exploração que se fez dos dados ao nível das diferentes variáveis poderá consultar a tese de doutoramento "Velhice na cultura contemporânea: um estudo sobre a perda emocional profunda", no repositório da Universidade de Aveiro.
} 
sobre as experiências de vida, incidindo, sobretudo, na infância e na adolescência. Esta etapa era fundamental para o indivíduo descontrair, reviver momentos significativos, rebuscar e revelar identidades passadas, mas, sobretudo, para se começar a construir a relação de confiança e de empatia entre entrevistado e entrevistadora. Na etapa seguinte, na fase central da entrevista, eram colocadas as perguntas mais complexas e concretas acerca da temática específica. Nestes momentos da narrativa, os sujeitos entrevistados reviviam a vida em comum com os seus cônjuges: as rotinas diárias, as dificuldades, as alegrias, as infelicidades e a sua morte, refletindo sobre os sentimentos vividos, os episódios mais relevantes do processo de luto e as práticas de superação. Na última fase da entrevista eram colocadas as questões mais fáceis e tranquilizantes. Quanto às perguntas relativas ao futuro, seguimos o conselho de Medrano e Cortés (2007) e, portanto, decidimos intercalá-las no decurso da entrevista, dada a complexidade e profundidade que poderiam representar para alguns sujeitos.

No protocolo de negociação inicial, os sujeitos deram a sua autorização para que as conversas pudessem ser audiogravadas, o que facilitou o posterior tratamento das mesmas. Assim, depois de realizadas as entrevistas, passava-se à fase da transcrição. Neste processo a principal preocupação era a de que a fidelidade do discurso se mantivesse e a significação do dito fosse perfeitamente percetível. Por fim, os textos eram submetidos à técnica de análise de conteúdo. Através da análise de conteúdo, procurámos, em cada redação, o conteúdo, o sentido e os sistemas de perceção, em suma, a compreensão do processo de significados que estava por trás da narrativa (Bardin, 2004). Assim, o pilar basilar da análise de conteúdo executada neste estudo foi a análise por categorias que, de acordo com Laurence Bardin (2004), é uma das mais utilizadas em dados qualitativos.

\subsection{Apresentação dos Resultados}

Partindo da análise de conteúdo das “mini-histórias de vida” (O’Neil, 2009) apresentamos os dados, tendo como eixos estruturais as temáticas que emergiram, transversalmente, nos discursos dos sujeitos do nosso estudo. Os dados apresentados neste artigo dizem apenas respeito à análise da variável "sexo".

Pretendemos, com a análise desta dimensão, perceber a influência que o sexo detém na significação da perda e na capacidade de adaptação e de (re)construção da práxis quotidiana. Neste sentido, a dimensão "sexo" será posta em relação com as três temáticas emergentes dos discursos e as respetivas categorias e subcategorias, conforme apresentado no quadro abaixo (ver quadro 1). 


\begin{tabular}{|c|c|c|c|}
\hline TEMÁticas & CATEGorias & \multicolumn{2}{|c|}{ SUBCATEGORIAS } \\
\hline \multirow{2}{*}{ SISTEMA FAMILIAR } & $\begin{array}{l}\text { 1.1. Relação com a fa- } \\
\text { mília alargada }\end{array}$ & & \\
\hline & $\begin{array}{l}\text { 1.2. O casamento - Tipo de } \\
\text { relação com o cônjuge falecido }\end{array}$ & & \\
\hline \multirow{6}{*}{$\begin{array}{l}\text { A VIDA NA ESTRUTU- } \\
\text { RA RESIDENCIAL }\end{array}$} & $\begin{array}{l}\text { 2.1. A institucionalização - } \\
\text { Impacto afetivo e emocional }\end{array}$ & & \\
\hline & \multirow{5}{*}{ 2.2. O quotidiano institucional } & \multicolumn{2}{|c|}{$\begin{array}{l}\text { 2.2.1 Qualidade dos cuidados de saú- } \\
\text { de, higiene e alimentação }\end{array}$} \\
\hline & & \multicolumn{2}{|c|}{ 2.2.2 Oferta de atividades de animação } \\
\hline & & \multirow{2}{*}{$\begin{array}{l}\text { 2.2.3 Relação com a } \\
\text { comunidade residencial }\end{array}$} & $\begin{array}{l}\text { 2.2.3.1 Relação com } \\
\text { os outros residentes }\end{array}$ \\
\hline & & & $\begin{array}{l}\text { 2.2.3.2 Relação com } \\
\text { os colaboradores }\end{array}$ \\
\hline & & \multicolumn{2}{|c|}{$\begin{array}{l}2.2 .4 \\
\text { Relação com a comunidade externa }\end{array}$} \\
\hline \multirow{2}{*}{ A PERDA } & \multirow{2}{*}{$\begin{array}{l}\text { 3.1. Mudanças provo- } \\
\text { cadas pela perda }\end{array}$} & \multicolumn{2}{|c|}{ 3.1.1 Solidão após a perda do cônjuge } \\
\hline & & \multicolumn{2}{|c|}{ 3.1.2 Solidão no quotidiano institucional } \\
\hline
\end{tabular}

Quadro 1 - Grelha de análise temática

\section{SISTEMA FAMILIAR}

Por sistema familiar entendemos a relação com a família largada — que engloba os familiares diretos e indiretos dos sujeitos da pesquisa - e o tipo de relação com o cônjuge falecido. Em seguida, apresentamos o quadro (Quadro 2) que sintetiza os dados relativamente ao sistema familiar.

\begin{tabular}{|c|c|c|c|c|}
\hline \multirow{2}{*}{ Categoria } & \multirow{2}{*}{ Nível } & \multicolumn{3}{|c|}{ Sexo } \\
\hline & & HOMENS & MULHERES & TOTAL \\
\hline \multirow{5}{*}{$\begin{array}{l}\text { RELACIONAMENTO COM } \\
\text { A FAMÍLIA ALARGADA }\end{array}$} & Muito bom & 4 & 6 & 10 \\
\hline & Médio & -- & -- & -- \\
\hline & Mau & -- & 3 & 3 \\
\hline & Inexistente & 1 & 1 & 2 \\
\hline & Total & 5 & 10 & 15 \\
\hline \multirow{5}{*}{$\begin{array}{l}\text { REPRESENTAÇÃO DA RELAÇÃO } \\
\text { COM O CÔNJUGE FALECIDO }\end{array}$} & Muito bom & -- & 6 & 6 \\
\hline & Médio & 5 & -- & 5 \\
\hline & Mau & -- & 4 & 4 \\
\hline & Inexistente & -- & -- & -- \\
\hline & Total & 5 & 10 & 15 \\
\hline
\end{tabular}

Quadro 2 - Sistema familiar, segundo o sexo

De acordo com os dados apresentados, verificamos a existência de dois padrões diferenciados, entre os sujeitos do sexo masculino e os sujeitos do sexo feminino, no que se refere às representações dos relacionamentos afetivos e emocionais.

Assim, podemos verificar que os homens perspetivam de forma mais positiva e satisfatória as suas relações com os familiares significativos do que as mulheres. No que se refere à relação com o cônjuge falecido, os sujeitos do sexo masculino manifestam 
uma tendência para representar a sua relação de forma moderada, enquanto as mulheres percecionam o seu relacionamento de forma mais extrema (muito bom/muito mau).

Passamos, de seguida à apresentação dos resultados relativos à temática "a perda do cônjuge".

\section{A PERDA DO CÔNJUGE}

Neste ponto, considerámos as representações dos sujeitos relativamente a duas grandes categorias decorrentes da perda do cônjuge: "solidão após a perda do cônjuge" e "estratégias facilitadoras de superação da perda".

Na categoria "solidão após a perda do cônjuge" foram analisadas as perceções dos sujeitos relativamente ao grau de solidão vivenciado após a morte do cônjuge — sentimento de vazio afetivo na sequência da perda de uma figura de ligação que proporcionava segurança, estabilidade e amparo. Na categoria "estratégias facilitadoras da superação da perda" analisámos as representações dos entrevistados sobre as estratégias que mobilizaram para auxiliar na superação da perda. As estratégias de apoio à superação do luto foram divididas em cinco tipos de atividades: atividades quotidianas/práticas, atividades sociais, atividades artísticas, atividades intelectuais/formativas e atividades espirituais/religiosas, conforme quadro abaixo (Quadro 3).

\begin{tabular}{|c|c|c|c|c|c|}
\hline \multirow{2}{*}{\multicolumn{2}{|c|}{ Categoria }} & \multirow[t]{2}{*}{ Nível } & \multicolumn{3}{|c|}{ Sexo } \\
\hline & & & HOMENS & MULHERES & TOTAL \\
\hline \multirow{5}{*}{\multicolumn{2}{|c|}{ SOLIDÃO APÓS A PERDA DO CÔNJUGE }} & Elevado & -- & 6 & 6 \\
\hline & & Moderado & 4 & 1 & 5 \\
\hline & & Leve & 1 & 3 & 4 \\
\hline & & Inexistente & -- & -- & -- \\
\hline & & Total & 5 & 10 & 15 \\
\hline \multirow{3}{*}{\multicolumn{2}{|c|}{$\begin{array}{l}\text { Atividades quotidianas/ } \\
\text { Práticas }\end{array}$}} & Sim & o & 5 & \\
\hline & & Não & 5 & 5 & \\
\hline & & Total & 5 & 10 & 15 \\
\hline \multirow{12}{*}{$\begin{array}{l}\text { ESTRATÉGIAS FACILI- } \\
\text { TADORAS DA SUPE- } \\
\text { RAÇÃO DA PERDA }\end{array}$} & \multirow{3}{*}{ Atividades sociais } & Sim & 4 & 6 & \\
\hline & & Não & 1 & 4 & \\
\hline & & Total & 5 & 10 & 15 \\
\hline & \multirow{3}{*}{ Atividades artísticas } & Sim & 2 & 3 & \\
\hline & & Não & 3 & 7 & \\
\hline & & Total & 5 & 10 & 15 \\
\hline & \multirow{3}{*}{$\begin{array}{l}\text { Atividades intelectuais/ } \\
\text { Formativas }\end{array}$} & Sim & 3 & 3 & \\
\hline & & Não & 2 & 7 & \\
\hline & & Total & 5 & 10 & 15 \\
\hline & \multirow{3}{*}{$\begin{array}{l}\text { Atividades espirituais/ } \\
\text { Religiosas }\end{array}$} & Sim & o & 5 & \\
\hline & & Não & 5 & 5 & \\
\hline & & Total & 5 & 10 & 15 \\
\hline
\end{tabular}

Quadro 3-A perda do cônjuge, segundo o sexo 
Tal como se pode constatar nos dados do quadro acima, as mulheres sentiram a solidão após a morte do cônjuge em maior número e grau do que os homens, que manifestaram sentimentos de solidão mais moderados, verificando-se, assim, um padrão diferenciado. Já no que se refere às estratégias facilitadoras da superação da perda, podemos observar a existência de quatro padrões diferenciados quanto às escolhas dos homens e das mulheres. Na realidade, segundo os dados apresentados, os homens admitem preferir as atividades artísticas e as atividades intelectuais/formativas, enquanto as mulheres sobrelevam as atividades quotidianas/práticas e as atividades espirituais/ religiosas. Relativamente às atividades sociais, apesar de ambos os sexos elegerem estas atividades como principal estratégia de adaptação, verificamos que este tipo de estratégia teve maior expressão para os homens do que para as mulheres.

Apresentaremos, de seguida (Quadro 4), os dados respeitantes às representações dos sujeitos do estudo quanto à vida na estrutura residencial, segundo o sexo.

\section{A VIDA NA ESTRUTURA RESIDENCIAL}

O tópico relativo à vida na estrutura residencial é constituído por duas grandes categorias: a institucionalização - nomeadamente, o impacto afetivo e emocional do processo - e o quotidiano institucional, que engloba a qualidade dos serviços de saúde, higiene e alimentação, a oferta de atividades de animação, a relação com a comunidade residencial e a relação com a comunidade externa.

De acordo com os dados apresentados, podemos verificar a existência de um conjunto de padrões diferenciados entre as representações dos homens e das mulheres no que se refere à vida na estrutura residencial. Logo num primeiro momento, os sujeitos do sexo masculino consideram que a entrada na instituição foi um processo mais fácil do que os sujeitos do sexo feminino. Também no tocante à relação com a comunidade residencial e com a comunidade externa à instituição, os entrevistados do sexo masculino perspetivam de forma mais positiva e satisfatória os relacionamentos que estabelecem, do que as entrevistadas de sexo feminino. Quanto à solidão experienciada em contexto institucional, apurámos que a tendência geral dos homens é para não se sentirem sós, enquanto a tendência feminina vai no sentido de as representações se dividirem entre os dois pontos mais díspares da tabela, existindo um número considerável de mulheres a percecionar como elevado o seu sentimento de solidão. Assim, os homens parecem desenvolver relações emocionais mais significativas e um menor grau de solidão, enquanto as mulheres têm representações, tendencialmente, mais negativas dos seus relacionamentos afetivos e apresentam uma tendência maior para se sentirem sós. 


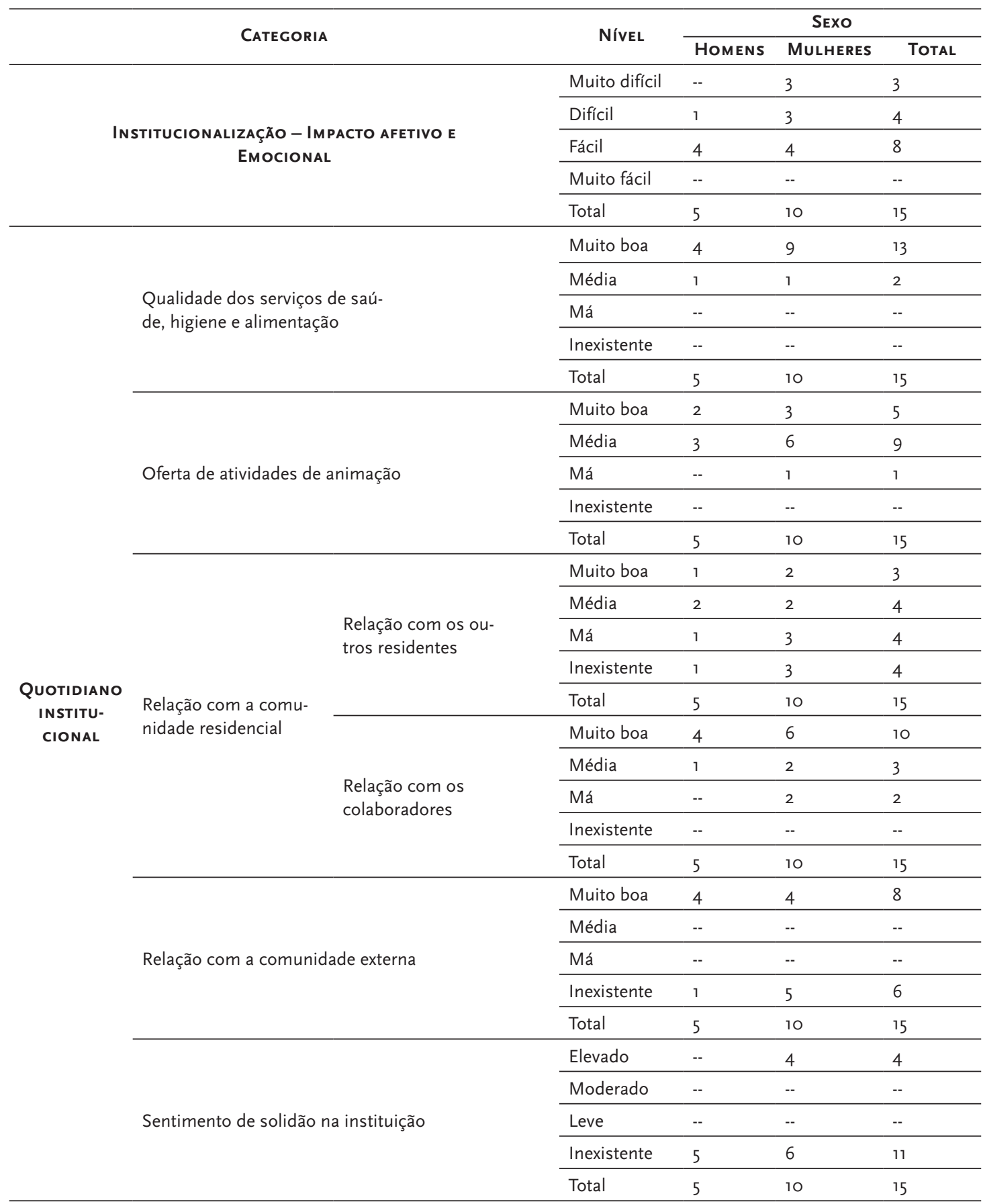

Quadro 4-A vida na estrutura residencial, segundo o sexo

\section{O SEXO COMO PRINCIPAL CONDIÇÃo CRÍTICA NA ADAPTAÇÃO À PERDA EMOCIONAL PROFUNDA: DISCUSSÃO DOS DADOS}

Nos discursos que os sujeitos participantes do estudo teceram sobre si mesmos emergiram diversos elementos-chave que, associados a condições pessoais e socioculturais específicas, se revelaram determinantes na forma como, em contextos institucionais, a superação do luto na idade adulta avançada é realizada. 
Neste sentido, e olhando desde uma perspetiva fenomenológica para a forma como os indivíduos se analisaram e refletiram sobre os seus atos e comportamentos, percebemos a existência de dois perfis diferenciados de reação perante as perdas emocionais profundas: um perfil adaptativo, orientado para comportamentos de superação da perda, e outro perfil não adaptativo, associado a uma postura de negação e de não superação da perda.

O perfil adaptativo diz respeito aos sujeitos que apresentam um perfil de tendência para a adaptação às perdas e às situações causadoras de stress, de reorganização emocional através de ligações afetivas e emocionais significativas, do desempenho de novos papéis e de mobilização de estratégias de apoio emocional. O perfil não adaptativo está associado aos sujeitos que não se adaptaram às perdas, interiorizando um perfil de desistência de reorganização emocional, dificultando a criação de laços e ligações afetivas, negando e evitando mudanças reestruturadoras.

Verificámos, ao longo da análise dos dados, que o género é uma condição determinante nos perfis de adaptação à perda, pois a investigação revelou padrões claramente diferenciados entre os discursos dos sujeitos masculinos e femininos. Destarte, os resultados do nosso estudo indicam que os homens revelam uma postura tendencialmente mais positiva de adaptação a eventos stressantes, relacionada com ligações afetivas mais satisfatórias e a uma maior perceção de controlo, enquanto as mulheres apresentam, tendencialmente, um padrão de maior fragilidade emocional, relações emocionais menos satisfatórias e uma menor perceção de controlo, que se reflete numa postura com maior propensão para a negação e para a desistência de adaptação à perda.

Com efeito, um dos aspetos determinantes da superação da perda é a perceção de controlo pois, conforme defendem Santos e Paúl (2006), as necessidades das pessoas que vivem em ambiente institucional são respondidas de forma tanto mais positiva quanto mais sólidas forem as redes sociais de apoio, nomeadamente as familiares. Na realidade, e tal como percebemos nos discursos dos nossos sujeitos, as relações afetivas com os familiares não diminuem de importância quando o sujeito é institucionalizado, continuando estas a ser decisivas na qualidade de vida das pessoas idosas e a constituir o eixo central do ciclo vital, espaço de pertença, de identificação e de continuidade na existência.

Não obstante, as relações familiares, e o suporte que delas provém, não são percecionadas de modo unânime pelos nossos sujeitos, emergindo padrões diferenciados no modo como os sujeitos masculinos e os sujeitos femininos percecionam as suas ligações familiares.

Assim, no que diz respeito aos homens, a grande maioria considera possuir uma relação muito boa com a família. Na realidade, estes sujeitos representam a ligação com os seus familiares como sendo de bastante proximidade, uma vez que se sentem, ainda, parte integrante da dinâmica familiar. Conforme os dados do estudo, os sujeitos masculinos, ao refletirem sobre a sua relação familiar, privilegiam o papel relacionado com o bem-estar material da família, aspeto que se concretiza, essencialmente, através do dinheiro: "gosto de ter aqui algum dinheiro porque às vezes vêm cá os meus netos, ou filhos [...] sou eu que lhes vou valendo quando eles precisam..." (Ent. 11, homem). 
Neste sentido, percebemos que os homens possuem uma representação da sua relação familiar tendencialmente mais instrumental, em que o seu papel está mais associado ao bem-estar — nomeadamente material e financeiro — da família: "o meu sobrinho costuma vir cá pedir-me opiniões acerca da agricultura, de negócios que está a pensar fazer... não me posso queixar da família que tenho!" (Ent. 6, homem). Na realidade, estes sujeitos perspetivam o seu papel na família, enquadrando-o na continuação da sua experiência de vida. Tal como foi referido na primeira parte do artigo, os sujeitos masculinos entrevistados são de uma geração altamente influenciada por papéis de género, em que cabia ao homem providenciar o sustento da família. Assim, tal como fizeram ao longo da sua vida, os entrevistados masculinos continuam a perspetivar-se na dinâmica familiar, tendo como base o apoio que podem fornecer a nível financeiro e de recursos.

Quando analisamos os discursos dos sujeitos do sexo feminino, compreendemos que as mulheres não percecionam as suas relações familiares de uma forma, tendencialmente, tão positiva como os homens. Em rigor, e tal como podemos observar no Quadro 2, um número considerável de mulheres perceciona as suas relações familiares em níveis negativos. Na realidade, para as entrevistadas, a satisfação com as relações familiares está intimamente relacionada com a presença constante e a proximidade afetiva dos seus familiares, necessitando, para o seu bem-estar, de sentir a comparência assídua destes na sua instituição de residência: "a mais velha [filha] veio no domingo passado e é natural que venha no próximo domingo. A mais nova [filha] é quem me faz as compras e veio ontem trazer-me a trouxa! E é assim! Normalmente vêm de 15 em 15 dias. Não passa desse tempo!" (Ent. 14, mulher). Quando a presença física é impossível, devido à distância geográfica que os separa, as mulheres atribuem uma elevada importância a sentirem-se objeto de cuidado e preocupação constantes por parte dos familiares: "eles [filho e netos] estão na Alemanha, mas falo muitas vezes com eles ao telefone. É praticamente todos os dias! E quando não ficam convencidos de que estou bem, pedem para falar com diretora! [risos] É assim, andam sempre preocupados!" (Ent. 9, mulher).

$\mathrm{Na}$ verdade, os sujeitos do sexo feminino que consideraram possuir uma relação negativa com a família apontaram como causa, precisamente, a ausência dos familiares e a falta de atenção e de afeto por parte destes, como podemos verificar nos três testemunhos seguintes: "a falta de carinho dos meus filhos é uma coisa que [choro] ... é uma coisa embrulhada, que me faz muita confusão!" (Ent. 2, mulher); "ajudei a criar os meus netos... morreu a mãe e agora já não me conhecem... [choro] não me conhecem como avó... não me vêm cá visitar nunca..." (Ent. 4, mulher); "olhe, então os meus filhos, que há sete anos que aqui estou e nunca me vieram ver! E tanto bem que eu lhes fiz! Fiz-Ihes tanto bem!" (Ent. 5, mulher). Com efeito, e à semelhança do que podemos verificar nos entrevistados masculinos, também as mulheres se perspetivam nas suas dinâmicas familiares a partir da sua experiência de vida. Em rigor, tendo estas mulheres sido socializadas para pensar e agir consoante os papéis de género tradicionais, competiam-lhes, então, maiores responsabilidades em cuidar, a nível afetivo e emocional, dos seus familiares. Assim, e tal como explicam diversos estudos (Neto, 2000, 2004; Carr et al, 2000; Guinther et al, 2003), as mulheres, especialmente desta geração, revelam possuir uma sensibilidade emocional mais aguda, muito ligada ao apoio afetivo que recebem. 
Estas diferentes representações quanto à satisfação com o relacionamento familiar repercutem-se, também, no tipo de exigências em que os sujeitos do estudo envolvem as suas famílias. Assim, enquanto os homens esperam que os seus familiares os integrem na dinâmica familiar, satisfazendo-os o papel de provedores de apoio financeiro, especialmente associado à perceção de controlo, as mulheres esperam atenções e cuidados contínuos nas dimensões emocionais e afetivas, exigindo a presença assídua dos familiares e a disponibilidade constante.

Estes padrões diferenciados entre as representações masculinas e as representações femininas são também visíveis no tocante às relações com os colaboradores das estruturas residenciais.

$\mathrm{Na}$ realidade, e tal como foi já referido, a comunidade residencial pode assumir-se, para a pessoa idosa enlutada, como um contexto privilegiado de desenvolvimento de relações interpessoais e de reinvestimento em novos relacionamentos e projetos de vida, contribuindo, indubitavelmente, para a sua reorganização emocional e qualidade de vida (Santos e Encarnação, 1998). Neste quadro, os profissionais das instituições desempenham um papel crucial no bem-estar do sujeito institucionalizado. Na verdade, em muitos casos, os colaboradores das instituições assumem o papel de uma nova família, com vínculos e relações diferentes, mas que são fundamentais para a qualidade de vida da pessoa idosa: "elas ajudam muito! São muito importantes nessas fases! Confortam-nos com palavras e estão sempre prontas para nos dar um miminho, um carinho..." (Ent.10, mulher).

Apesar de todos os sujeitos do nosso estudo atribuírem uma grande importância a estes cuidadores, a verdade é que a relação com os colaboradores é perspetivada de forma mais positiva pelos sujeitos masculinos e menos satisfatória pelos sujeitos femininos. Tal como explica Félix Neto $(2004,2000)$, este aspeto parece estar relacionado com o facto de as mulheres serem mais críticas e apresentarem mais respostas emocionais que os homens, o que acaba por influenciar o tipo de relações que são desenvolvidas com os outros.

Reiteramos (Bennet, 1997; Parkes, 1998; Rebelo, 2009, 2007) a importância, no processo de adaptação à perda, da (re)construção de novos afetos, sendo a perceção de apoio e amparo um determinante crucial no processo de superação do luto. Este aspeto é tão premente nos discursos dos nossos sujeitos, que fica vincada a ideia de que as redes sociais de apoio influem diretamente na qualidade de vida da pessoa em luto, como conseguimos perceber pelo seguinte testemunho: "não tenho ninguém... [...] então fico aqui sozinha... desde que fiquei viúva perdi o pio... sinto-me muito triste” (Ent. 7, mulher).

Numa sociedade profundamente individualista, o "nós" possui especial valor no que respeita ao sentido de pertença e de identidade; por isso, para além da importância que adquirem as relações com os familiares significativos e com os colaboradores da estrutura residencial de acolhimento, as próprias redes de apoio informal, constituídas pelos amigos, vizinhos e comunidade, são, também elas, fulcrais. Com efeito, e conforme podemos verificar nos discursos dos entrevistados, ao reatar ligações a espaços e contextos vivenciais comunitários, os sujeitos experimentam o sentimento de controlo, aspeto intimamente relacionado com a identidade do indivíduo e com a sua capacidade de adaptação às perdas: "eu faço a minha vida normal, não estou sempre aqui! [...] Vou 
muitas vezes até minha casa: tenho lá documentos importantes e muitos apontamentos. E aproveito para visitar pessoas e para pôr a conversa em dia!" (Ent. 3, homem).

De acordo com Silva (2005), as relações com o exterior da estrutura de acolhimento oferecem uma certa perceção de continuidade, necessária para enfrentar as mudanças experimentadas, oferecendo um equilíbrio satisfatório que atenua o impacto psicológico das perdas. Contudo, os dados revelam padrões diferenciados nas representações dos homens e das mulheres relativamente à sua relação com a comunidade exterior.

$\mathrm{Na}$ realidade, os homens percecionam de uma forma, tendencialmente, mais positiva e satisfatória as ligações que mantêm com a comunidade envolvente do que as mulheres, que possuem representações tendencialmente menos satisfatórias.

Mesmo após a entrada definitiva na estrutura residencial, os dados sugerem que os homens usufruem de uma rede de relações sociais mais amplas e mais profundas na comunidade ("eu fiz parte da direção de várias associações, andavam sempre a empurrar-me para essas coisas [risos] estive metido em muitas coisas até vir para aqui! Por isso, quando saio encontro sempre gente conhecida" (Ent. 3, homem)) do que as mulheres, cujos contactos sociais se centram, maioritariamente, nas relações com os familiares significativos: "desde que aqui entrei saí muito poucas vezes e foi só para ir almoçar a casa dos meus filhos! Também, onde mais havia de ir?" (Ent. 2, mulher).

$\mathrm{Na}$ verdade, enquanto os homens do nosso estudo veem o seu espaço de pertença ser mais associado "à rua", as mulheres percebem-se mais confinadas ao espaço "da casa", o que influí amplamente no tipo de relações sociais estabelecidas: os sujeitos masculinos possuem contactos sociais mais abrangentes e dispersos pela comunidade, enquanto os sujeitos femininos detêm contactos sociais mais restritos e mais centrados na família e vizinhos.

Os resultados do nosso estudo sugerem que os padrões diferenciados que aparecem recorrentemente nas representações masculinas e femininas relativamente à esfera relacional estão relacionados com uma forte questão de género, demonstrando que são as mulheres que se representam, tendencialmente, menos apoiadas e amparadas quer pelos familiares, quer pelos colaboradores da estrutura residencial, quer ainda, pela comunidade externa à instituição de acolhimento.

$\mathrm{Na}$ verdade, reiteramos o facto dos entrevistados participantes desta pesquisa serem "sujeitos de transição", indivíduos de pertença a um contexto histórico e sociocultural, de caraterísticas tradicionais, onde a sociabilidade e a forma de existência era acomodada a diferentes espaços de pertença (Santos \& Encarnação, 1998). Com efeito, os sujeitos do nosso estudo nasceram na segunda década do século passado, e viveram durante um período da história portuguesa - o Estado Novo - em que os papéis de género eram condicionadores das práticas e das formas de ser e estar em sociedade. Assim, enquadrados em papéis sociais diferenciados, consoante o seu sexo, muitos dos comportamentos eram adquiridos, tendo como base as diferenças a nível de traços que eram aceites como sendo de mulher e de homem, influenciando o comportamento, o autoconceito e a perceção dos outros (Neto, 2000), em suma, afetando uma postura específica no processo de adaptação à perda. 
Desta forma, os dados do estudo sugerem que as relações interpessoais, e a consequente rede de suporte afetivo e emocional, são perspetivadas pelos sujeitos do sexo masculino enquanto contextos sociais de apoio que favorecem estratégias facilitadoras no processo de superação do luto. O "ser-no-mundo", que implica "ser-com-os-outros" - quer seja família, colegas residentes, colaboradores ou comunidade exterior -, é representado pelos sujeitos do sexo masculino de forma desproblematizada, perspetivando-se em relações que não apresentam dificuldades e que contribuem para o seu enriquecimento.

No que se refere às mulheres, percebemos, nas narrativas das entrevistadas, uma maior tendência para representações negativas e insatisfatórias da sua rede de relacionamentos, e uma maior incapacidade em tornar as ligações afetivas existentes em estratégias de suporte de adaptação à perda.

Em rigor, percebemos que as mulheres objeto do nosso estudo, ao mesmo tempo que perspetivam as relações interpessoais de forma mais emotiva e expressiva, revelam, também, uma maior tendência para a debilidade afetiva quando se pensam no seu círculo de relações. Tudo indica que esta questão está relacionada com a precariedade emocional em que muitas destas mulheres viveram até à idade adulta avançada, e que pode ter dado origem a um conjunto de dificuldades sociais e afetivas. Na verdade, quando as nossas entrevistadas se narram no âmbito das suas relações sociais, esta incompetência social e afetiva é visível, logo desde o primeiro momento, nas representações quanto ao relacionamento com o cônjuge falecido. Com efeito, as perceções negativas que emergem associadas ao relacionamento conjugal são replicadas no modo como descrevem o quotidiano na instituição e o próprio processo de institucionalização: na realidade, estas mulheres apresentam as piores relações com os familiares significativos, com os colaboradores e com a comunidade externa, revelando, enfim, maiores níveis de solidão, quando comparados com os sujeitos do sexo masculino. Percebemos, então, que as mulheres apresentam tendencialmente, uma maior fragilidade emocional na forma como se relacionam com os outros, o que influencia o tipo de apoio emocional e afetivo que retiram dessas relações, provocando maiores dificuldades de reconhecimento de pertença e uma menor perceção de controlo da sua vida, influindo fortemente na capacidade de se adaptarem às perdas e de se organizarem emocionalmente.

Gostaríamos de salientar, ainda, que estas diferenças entre sexos não são apenas notórias nos relacionamentos sociais, mas, também, na natureza das estratégias de apoio que são escolhidas e na forma como estas são utilizadas na adaptação à perda.

$\mathrm{Na}$ realidade, os diversos padrões diferenciados que emergem entre os entrevistados femininos e os entrevistados masculinos, e que podem ser analisados no Quadro 3, levam-nos a levantar a questão de se saber se os sujeitos femininos deste estudo não terão escolhido estratégias e modos de superação específicos, mais limitados e condicionados, por possuírem menores capacidades e aptidões para fazerem uso de atividades mais profícuas no seu processo de adaptação à perda: "agarrei-me a Deus! Havia mais alguma coisa que pudesse fazer? Não!" (Ent. 2, mulher) do que os homens que recorreram a atividades mais diversificadas e de maior potencial adaptativo: "para 
não pensar em coisas más tenho de estar entretido... então, gosto muito de cantar umas cantiguitas, e ponho-me na sala a cantar uns fados inventados por mim! [risos] Olhe, ainda agora estava lá em cima no quarto e quando me ponho a pensar em coisas más, gosto de escrever poemas ou canções! [tira um conjunto de papéis do bolso] olhe, tenho aqui uma música, quer ouvir?" (Ent. 12, homem)

Com efeito, tudo aponta para, uma vez mais, estarmos perante questões de género, que parecem influenciar fortemente o processo de desenvolvimento, de adaptação e de resiliência dos sujeitos participantes. Na verdade, e tal como já foi discutido, as pessoas idosas de hoje continuam a reconhecer-se em papéis de género, enformados por aspetos sociais e construídos culturalmente, que influenciam o comportamento, as vivências e as representações face à vida e às ligações emocionais que lhe dão sentido (Neto, 2004, 2000; Parkes, 1998; Santos e Encarnação, 1998). Assim, os homens e as mulheres deste estudo viveram de formas diferentes - atendendo aos papéis de género que condicionaram as suas experiências e as suas formas de sociabilidade - e, por isso, na velhice também apresentam caraterísticas diferenciadas de adaptação à perda.

Tal como já foi discutido no início do artigo, encontramos na literatura estudos (Erlangsen et al, 2004; Stroebe, 1998) que revelam que os homens idosos têm maiores dificuldades em elaborar a perda da companheira e que precisam de mais tempo para superar o luto, e que as mulheres têm maiores facilidades de se adaptarem à perda do cônjuge (Carr et al, 2000;), alertamos para o facto de estes estudos terem sido feitos com pessoas idosas não institucionalizadas. Assim, quando se afirma que as mulheres se adaptam melhor porque têm mais facilidade em gerir a casa, em tratar das lides domésticas ou porque mantêm uma rede mais forte de socialização com os vizinhos e familiares (Guinter, Segal \& Boggaards, 2003), estes recursos e estratégias não se aplicam às mulheres institucionalizadas que não podem colaborar nas lides domésticas, que não podem fazer usos dos seus saberes e que veem ser rompidas as ligações à comunidade e aos vizinhos. Por outro lado, os homens veem as suas necessidades diárias serem asseguradas (como, de resto, aconteceu ao longo de toda a sua vida) e como possuem uma rede mais larga e satisfatória de relacionamentos, sentem-se mais enquadrados e revelam maiores facilidades de adaptação à perda.

\section{CONCLUSÕES E RECOMENDAÇõES}

À luz dos resultados a que este estudo conduziu, percebemos que as relações sociais são fundamentais na reorganização emocional e na superação do luto, e que o quotidiano das pessoas idosas, embora institucionalizadas, continua a estar assente em redes de solidariedades, internas e externas à instituição, que favorecem a participação social e a promoção da sua própria cultura.

Percebemos, também, que as condições sociais e culturais influenciam o modo como o/a enlutado/a se adapta à perda e supera o luto e, apesar de não existirem categorias universais para organizar o processo de luto, os resultados desta investigação mostram que o género parece ser determinante, enquanto condição crítica que favorece um perfil de maior ou menor adaptação à perda. 
Assim, enquanto os sujeitos do sexo masculino apresentam um perfil orientado para uma reestruturação mais adaptativa e equilibrada, com uma maior ligação afetiva e emocional aos familiares, colaboradores e comunidade externa à instituição, sentindo-se, também, menos sós na estrutura residencial, as mulheres por nós estudadas apresentam um perfil mais orientado para a perda, onde emergem, tendencialmente, padrões de mais fraca ligação com os familiares, com a comunidade residencial e com a comunidade externa à residência, sendo, também, as mulheres a sentirem-se mais sós na instituição de acolhimento.

Assumindo a existência de uma relação indissociável entre cultura, luto e enveIhecimento (Papalia et al., 2006), pudemos concluir que não só as perdas são vividas cultural e simbolicamente de forma diferenciada por homens e mulheres, mas, também, as respostas que são dadas aos aspetos que envolvem a superação da perda são determinadas por questões associadas aos papéis de género culturalmente assimilados.

Assim, e para que a institucionalização não se converta em outra perda emocional profunda, a estrutura residencial deve possibilitar aos sujeitos o acesso a diferentes estratégias de apoio na superação do luto, ancoradas nas experiências de vida de cada sujeito. A intervenção realizada nestas estruturas deve reconhecer a individualidade de cada pessoa idosa, que não se pode alhear do todo, uma vez que as vidas são vividas de forma interdependente e moldadas pelas influências socioculturais. Para além disso, os profissionais das instituições devem prestar especial atenção aos sujeitos que apresentem um perfil de não adaptação à perda, para que, através de uma intervenção adequada e coerente com o universo social e cultural do residente, se consiga contrariar a tendência de desistência e não (re)construção identitária, potenciando a agência e o controlo da sua vida.

\section{REFERÊNCIAS}

Afonso, M. (2012). Stress, coping e resiliência em pessoas idosas. In C. Paúl \& O. Ribeiro (Coord.), Manual de Gerontologia: Aspetos Biocomportamentais, Psicológicos e Sociais do Envelhecimento (pp. 163-175). Lisboa: Lidel,

Bardin, L. (2004). Análise de conteúdo. Lisboa: Edições 70. Tradução de Luís Antero Reto e Augusto Pinheiro.

Barreto, J. (2006). Relação terapêutica com o paciente idoso. In H. Firmino (Ed.), Psicogeriatria (pp. 113-132), Coimbra: Psiquiatria Clínica.

Barros de Oliveira, J. (2010 [ $4^{\mathrm{a} e d i c ̧ a ̃ o]) . ~ P s i c o l o g i a ~ d o ~ e n v e l h e c i m e n t o ~ e ~ d o ~ i d o s o . ~ P o r t o: ~ L i v p s i c . ~}$

Bennet, K. M. (1997). Widowhood in elderly women: The medium-and long-term effects on mental and physical health. Mortality, 2(2),137-149.

Bennet, K. M. (1998). Longitudinal changes in mental and physical health among elderly, recently widowed Men. Mortality, 3(3), 265-274.

Bertaux, D. (1999). El enfoque biográfico: su validez metodológica, sus potencialidades. Proposiciones, 29, 1-22. Acedido em http://www.sitiosur.cl/publicacionescatalogodetalle.php?PID=3258\&doc=\&lib=\&rev=\& art $=\& d o c 1=\&$ vid $=\&$ autor $=\&$ coleccion $=\&$ tipo $=A L L \&$ nunico $=15000029$ 
Bowlby, J. (1984). Loss: Sadness and depression. Vol. 3. Nova Yorque: Basic Books.

Born, T. (2002). Cuidado ao idoso em instituição. In M. Netto (Org.), A Velhice e o Envelhecimento em Visão Globalizada (pp. 403-414). São Paulo: Editora Atheneu.

Bourdieu, P. (1989). O poder simbólico. Lisboa: Difel. Tradução de: Fernando Tomaz.

Brandão, A. (2007). Entre a vida vivida e a vida contada: A história de vida como material primário de investigação sociológica. Configurações. Revista de Ciências Sociais. 3, 83-106. Acedido em http:// repositorium.sdum.uminho.pt/bitstream/1822/9630/3/Entre\%20a\%20Vida\%20Vivida\%20(2).pdf

Carr, D. (2004). Gender, preloss marital dependence, and older adults' adjustment to widowhood. Journal of Marriage and Family, 66, 220-235.

Carr, D., House, J., Kessler, R., Nesse, R., Sonnega, J. \& Wortman, C. (2000). Marital quality and psychological adjustment to widowhood among older adults: A longitudinal analysis. Journal of Gerontology: Social Sciences, 55 B(4), 197-207.

Carr, D., \& Bodnar-Deren, S. (2009). Gender, aging and widowhood. In P. Uhlenberg (Ed.), International Handbook of Population Aging (pp. 705-728), New York: Springer-Verlag. doi:10.1007/978-1-4020-8356-3-32.

Erlangsen, A., Jeune, B, Bille-Brahe, U \& Vaupel, J. (2004). Loss of partner and suicide risks among old: a population-based register study. Age and Ageing. 33 (4), 378-383. doi: 10.1093/ageing/afh128.

Ferrarotti, F. (2007). Las historias de vida como método. Convergência. Revista de Ciências Sociais, 44 (14), 1540. Acedido em http://www.redalyc.org/articulo.oa?id=10504402

Fry, P.S. (1998). Spousal loss in late life: A 1-year follow-up of perceived changes in life meaning and psychosocial functioning following bereavement. Journal of Personal and Interpersonal Loss, 3, 369-391.

Gomes, A. (2010). Envelhecimento: Memórias da velhice pelas terras do sempre e do nunca. Lisboa: Santa Casa da Misericórdia.

Guinter, P., Segal, D. \& Boggaards, J. (2003). Gender diferences in emotional processing among bereaved older adults. Journal of Loss andTrauma, 8, 15-33.

Ha, J., Carr, D., Utz, R. \& Nesse, R. (2006). Older adults' perceptions of intergenerational support after widowhood - How do men and women differ?. Journal of Family Issues, 27(1), 3-30.

Mcgoldrick, M. \& Walsh, F. (1998). Um tempo para chorar: A morte e o ciclo de vida familiar. In F. Walsh \& M. Mcgoldrick (Coord.), Morte na Família: Sobrevivendo às Perdas (pp. 56-75). Porto Alegre: Artmed. Tradução de Cláudia Dornelles.

Medrano, C. \& Cortés, A. (2007). La investigación narrativa y su relación com la educación. In C. Medrano (Coord.), Las Histórias de Vida. Implicaciones Educativas (pp. 21-46). Buenos Aires: Alfagrama,

Neto, F. (2000). Psicologia social. Volume 2. Lisboa: Universidade Aberta.

Neto, F. (2004). Psicologia social da felicidade. In F. Neto (Coord.), Psicologia Social Aplicada (pp. 351-392), Lisboa: Universidade Aberta.

O' Neil, B. J. (2009). Histórias de vida em antropologia: estilos e visões, do etnográfico ao hipermoderno. In E. Lechner (Org.), Histórias de Vida: Olhares Interdisciplinares (pp. 109-117), Porto: Edições Afrontamento. 
Papalia, D., Olds, S. \& Feldman, R. (2006[8ªedição]). Desenvolvimento humano. Porto Alegre: Artmed. Tradução de Daniel Bueno.

Parkes, C. M. (1998). Luto - Estudos sobre a perda na vida adulta. São Paulo: Summus Editorial. Tradução Maria Helena Franco Bromberg.

Paúl, C. (1997). Lá para o fim da vida. Coimbra: Livraria Almedina.

Paúl, C. (2006). Psicologia do envelhecimento. In H. Firmino (Ed.), Psicogeriatria (pp. 43-65), Coimbra: Psiquiatria Clínica.

Rebelo, J. E. (2007[3 $3^{\mathrm{a}}$ edição]). Desatar o nó do luto: Silêncios, receios e tabus. Lisboa: Casa das Letras.

Rebelo, J. E. (2009). Amor, luto e solidão. Lisboa: Casa das Letras.

Ribeiro, A. (2002) Sexualidade na terceira idade. In M. Netto (Org.), A Velhice e o Envelhecimento em Visão Globalizada (pp. 124-135), São Paulo: Editora Atheneu.

Santos, F. \& Encarnação, F. (1998). Modernidade e gestão da velhice. Faro: Centro Regional da Segurança Social do Algarve.

Silva, M. E. (2005). Saúde mental e idade avançada. In C. Paúl \& A. Fonseca (Coord.), Envelhecer em Portugal (pp. 137-156). Lisboa: Climepsi Editores.

Stroebe, M. S. (1998). New directions in bereavement research: Exploration of gender differences. Palliative Medicine, 12, 5-12.

Twycross, R. (2003 [ $2^{\mathrm{a} e d i c ̧ a ̃ o]) . ~ C u i d a d o s ~ p a l i a t i v o s . ~ L i s b o a: ~ C l i m e p s i ~ E d i t o r e s . ~ T r a d u c ̧ a ̃ o ~ d e ~ J o s e ́ ~ N u n e s ~ d e ~}$ Almeida.

Worden, W, J. (2002). Grief counselling and grief therapy - A handbook for the mental health practitioner. Nova Yorque: Springer Publishing Company.

Jenny Gil Sousa é doutorada em Estudos Culturais pelas Universidades do Minho e de Aveiro, mestre em Arte e Educação pela Universidade Aberta e licenciada em Animação Socioeducativa pelo Instituto Politécnico de Coimbra. É docente na Escola Superior de Educação e Ciências Sociais do Instituto Politécnico de Leiria e coordena o Núcleo de Leiria da Rede Iberoamericana de Animação Sociocultural. É investigadora do CECS - Centro de Estudos de Comunicação e Sociedade da Universidade do Minho e membro do NIDE do Instituto Politécnico de Leiria.

E-mail: jgil.sousa@gmail.com

Escola Superior de Educação e Ciências Sociais - IPLeiria / CECS (Centro de Estudos de Comunicação e Sociedade) Universidade do Minho Campus de Gualtar, 4710057, Braga, Portugal

Maria Manuel Rocha Teixeira Baptista é docente e investigadora em Estudos Culturais no Departamento de Línguas e Culturas da Universidade de Aveiro e Directora do Programa Doutoral em Estudos Culturais da Universidade de Aveiro $\left(3^{\circ}\right.$ ciclo leccionado em colaboração com a Universidade do Minho). Com obra diversa, publicada nacional e internacionalmente, na área dos Estudos Culturais, é doutorada em Cultura, pela 
Universidade de Aveiro, desde 2002, é mestre em Psicologia da Educação pela Faculdade de Psicologia e Ciências da Educação da Universidade de Coimbra, 1996 e Licenciada em Filosofia pela Faculdade de Letras da Universidade do Porto, 1986.

E-mail:mbaptista@ua.pt

Departamento de Línguas e Culturas - CLLC (Centro de Línguas Literaturas e Culturas) Universidade de Aveiro Campus Universitário de Santiago, 3810-193, Aveiro, Portugal

* Submetido: 16-02-2015

* Aceite: 20-04-2015 